\title{
An improved fluorometric leukocyte $\beta$-glucosidase assay for Gaucher's disease
}

\author{
Lydia B. Daniels ${ }^{a}$, Robert H. Glew ${ }^{\mathrm{a}, *}$, Warren F. Diven ${ }^{\mathrm{b}}$, Robert E. Lee ${ }^{\mathrm{b}}$ \\ and Norman S. Radin ${ }^{\mathrm{c}}$ \\ ${ }^{a}$ Department of Biochemistry and ${ }^{b}$ Department of Pathologv, University of Pittsburgh School of Medicine, \\ Pittsburgh, PA 15261 (U.S.A.), and ${ }^{\mathrm{C}}$ Mental Health Research Institute (Department of Psychiatry), \\ University of Michigan, Ann Arbor, MI 48109 (U.S.A.)
}

(Received January $30 \mathrm{th}, 1981$ )

\section{Summary}

Three fluorometric leukocyte $\beta$-glucosidase assays were compared for their ability to diagnose Gaucher's disease and identify carriers of the disorder: the acid $\beta$-glucosidase assay of Beutler and Kuhl [2], a pH 5.5-sodium taurocholate-dependent assay and a new procedure which employs conduritol B epoxide, an active-site specific inhibitor of glucocerebrosidase. All three assays unambiguously identified patients with Gaucher's disease. With regard to identifying carriers the bile saltdependent assay of Peters et al. and the conduritol B epoxide-dependent procedure gave the greatest discrimination between the mean $\beta$-glucosidase values for the control and heterozygote samples when evaluated using Student's $t$ test. The most reliable assay for the identification of the carrier state was the conduritol B epoxide-dependent procedure which can be expected to provide the fewest false negative results when classifying heterozygotes (5\%). However, the fact that none of these methods will completely separate control and heterozygote samples indicates that their use in screening programs will result in a significant number of incorrect assignments.

\section{Introduction}

Gaucher's disease is an autosomal recessive sphingolipidosis that involves the storage of glucocerebroside in cells of the reticuloendothelial system [1]. Although the disease presents in a visceral, non-cerebral form (type 1) or in forms with extensive central nervous system involvement (type 2 and type 3 ), all patients with Gaucher's disease are profoundly deficient in lysosomal glucocerebrosidase. Tissues of heterozygotes contain approximately half as much glucocerebrosidase as the

* To whom correspondence should be addressed. 
corresponding tissues from homozygous normal individuals.

Confirmation of Gaucher's disease, as well as carrier detection, by biochemical means can be accomplished using a glucocerebrosidase assay that employs the radiolabeled authentic substrate, glucocerebroside, and fibroblasts or leukocytes as a source of enzyme; however, this assay is time-consuming and relatively expensive. Alternatively, one can evaluate the relative glucocerebrosidase content of tissues using a more convenient $\beta$-glucosidase assay that employs the non-physiologic, fluorogenic substrate 4-methylumbelliferyl- $\beta$-D-glucopyranoside. One such method is that described by Beutler and Kuhl [2] (Procedure C) which is referred to as the " $\mathrm{pH}$ $4.1 \beta$-glucosidase" assay. An alternative fluorometric assay described by Peters et al. [3] (Procedure B) has proven useful in confirming the diagnosis of Gaucher's disease and in carrier detection; the assay is performed at $\mathrm{pH} 5.5$ and the incubation medium is supplemented with sodium taurocholate.

Recently, we reported on a revised "pH 5.5-taurocholate" assay that incorporates an active site inhibitor of glucocerebrosidase, conduritol $B$ epoxide (CBE), into the incubation medium [4]. Using this newer method, designated the "CBE-dependent $\beta$-glucosidase" assay (Procedure A), we demonstrated for the first time that under appropriate conditions it was possible to use the fluorogenic substrate to confirm the diagnosis of Gaucher's disease when a liver homogenate served as the source of enzyme. The success of the assay was based on the ability of CBE to inhibit glucocerebrosidase without affecting the activity of a second, broad specificity $\beta$-glucosidase which is present in most human tissues, including leukocytes, but which does not utilize glucocerebroside as a substrate. The difference in $\beta$-glucosidase activities expressed when determinations are performed in the presence and absence of CBE provides a measure of the glucocerebrosidase content of tissue extracts.

This report presents the results of a study in which the performance of the new "CBE-dependent $\beta$-glucosidase" assay was compared with both the "pH $4.1 \beta$ glucosidase" procedure and the "pH 5.5 taurocholate" assay in terms of diagnosing Gaucher's disease and identifying carriers of the disorder, using leukocytes as the source of enzyme.

\section{Materials}

Pure sodium taurocholate was obtained from ICN Pharmaceuticals, Inc.; 4methylumbelliferyl- $\beta$-D-glucopyranoside was obtained from Koch-Light Laboratories, Ltd. Conduritol B epoxide was prepared according to Vunnam and Radin [5].

\section{Methods}

Leukocytes. Venous blood samples $(20-25 \mathrm{ml})$ were obtained from normal individuals, obligate heterozygotes and patients with type 1 Gaucher's disease. EDTA-containing tubes were used to prevent coagulation. Blood samples were collected and leukocytes prepared as described previously [3]. The resulting leukocyte pellet was suspended in $1 \mathrm{ml}$ of $9.0 \mathrm{~g} / 1$ sodium chloride and sonicated at $4^{\circ} \mathrm{C}$ for $4 \mathrm{~s}$ using a Heat Systems-Ultrasonics sonicator (Model W-220F) at setting 4 
using the macrotip immediately prior to performing enzyme assays.

Three $\beta$-glucosidase assays were employed in the present study, all of which utilized 4-methylumbelliferyl- $\beta$-D-glucopyranoside as the substrate. Assays were performed in series on a single day. The " $\mathrm{pH} 5.5$-taurocholate" assay was performed as described elsewhere [3] and the "pH $4.1 \quad \beta$-glucosidase" assay was carried out according to Beutler and Kuhl [2].

The recently developed "CBE-dependent $\beta$-glucosidase" assay is a modification of the "pH 5.5-taurocholate" assay and relies upon conduritol B epoxide to distinguish between glucocerebrosidase and a soluble, non-specific $\beta$-glucosidase. It has been shown that sodium taurocholate partially inhibits the non-specific $\beta$ glucosidase and activates glucocerebrosidase [3]. Thus, measurement of $\beta$-glucosidase activity in the presence of the bile salt determines both glucocerebrosidase and residual $\beta$-glucosidase activity that is not inhibited by sodium taurocholate. Conduritol B epoxide at $2 \mathrm{mmol} / \mathrm{l}$, in the presence of sodium tauroctiolate, will inhibit more than $95 \%$ of the glucocerebrosidase activity in crude tissue homogenates but will not affect the activity of the non-specific $\beta$-glucosidase. Therefore, performance of the "pH 5.5-taurocholate" $\beta$-glucosidase assay in the presence of CBE measures only the residual activity of the broad specificity $\beta$-glucosidase. The difference between these two determinations is thus a measure of $\beta$-glucocerebrosidase activity. Specifically, the assay medium contains $5 \mathrm{mmol} / \mathrm{l}$ 4-methylumbelliferyl- $\beta$-Dglucopyranoside, $0.2 \mathrm{~mol} / 1$ sodium acetate buffer, $\mathrm{pH} 5.5,10 \mu \mathrm{l}$ of tissue extract (approximate protein content 20-100 $\mu \mathrm{g}$ ), and either distilled water (minus CBE) or CBE to a final concentration of $2 \mathrm{mmol} / 1$ (plus CBE) in a final volume of $0.1 \mathrm{ml}$. Incubations are carried out at $37^{\circ} \mathrm{C}$ for $1 \mathrm{~h}$ with gentle shaking. Preincubation of the enzyme with $\mathrm{CBE}$, at either $4^{\circ} \mathrm{C}$ or room temperature for up to $1 \mathrm{~h}$ does not increase the extent of inhibition by $\mathrm{CBE}$.

Reactions are terminated by the addition of $2.9 \mathrm{ml} \mathrm{NH}_{4} \mathrm{OH}$-glycine buffer, $\mathrm{pH}$ 10.5, and fluorescence is determined as previously described [3]. One unit of enzyme activity is defined as that amount of enzyme which cleaves $1 \mathrm{nmol}$ glucose from the substrate per hour, at $\mathrm{pH} 5.5$ and $37^{\circ} \mathrm{C}$.

Protein determination. Protein was estimated by the method of Bradford [6] using bovine serum albumin as standard.

\section{Results and discussion}

The three $\beta$-glucosidase assays described above were performed on extracts of leukocytes from 3 samples consisting, respectively, of 22 normal individuals, 11 obligate carriers of Gaucher's disease (i.e., parents of patients), and five patients with the adult form of the disease. The results of these determinations are presented graphically in Fig. 1 and summarized in Table I. Fig. 1 illustrates the range of $\beta$-glucosidase values obtained for each sample as a function of assay procedure. The mean value obtained for the control individuals is indicated in each case, along with the standard deviation.

For all three assay procedures there was no overlap of the ranges of $\beta$-glucosidase values observed for the Gaucher's disease patients and the obligate heterozygotes. 


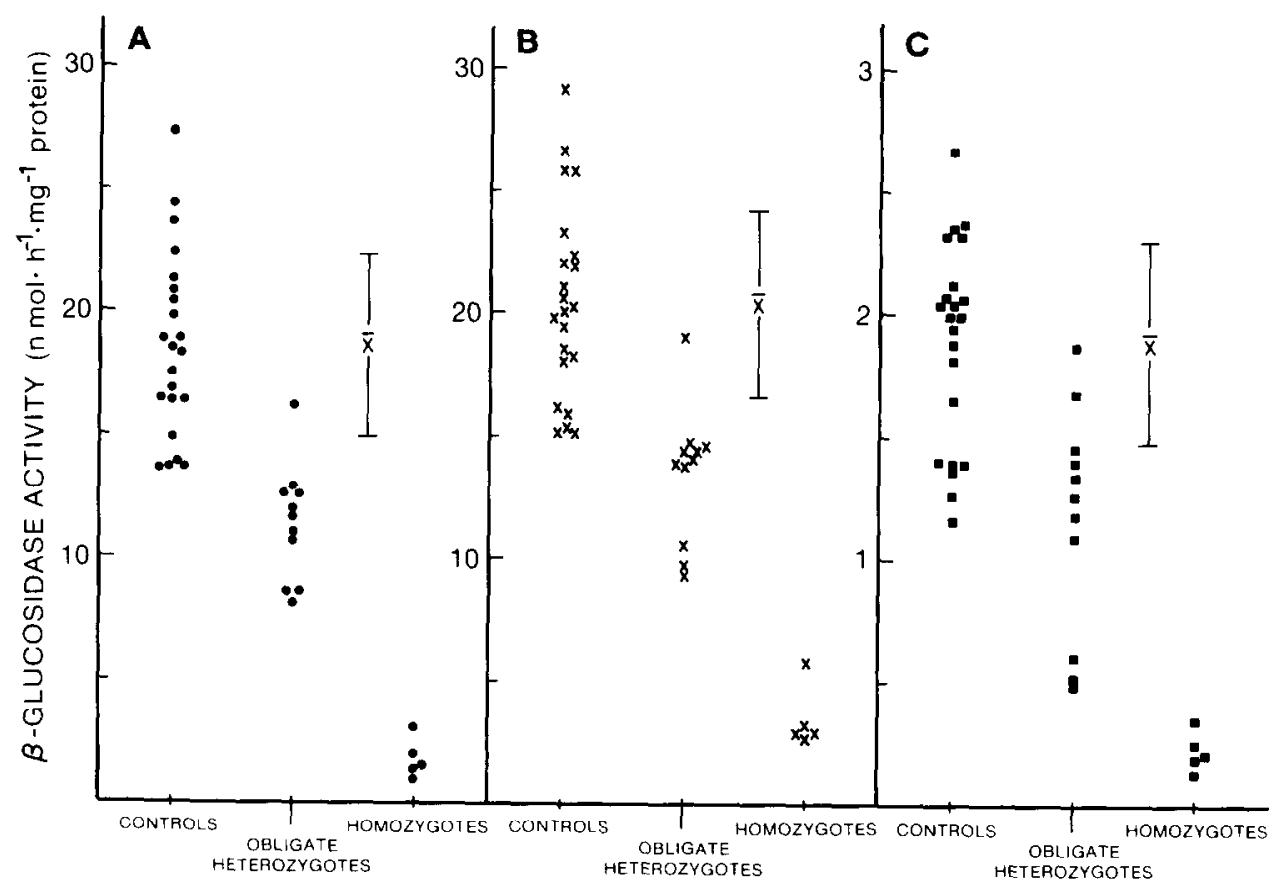

Fig. 1. The range of $\beta$-glucosidase activity observed in human leukocytes as a function of the assay procedure followed. Human leukocytes, isolated as described under Methods, were used as the source of $\beta$-glucosidase for three assays: Daniels et al. (A) [4]. Peters et al. (B) [3], and Beutler and Kuhl (C) [2]. The range of activity values for normal subjects, obligate heterozygotes and patients with Gaucher's disease (type l) are indicated. For each method, the mean $\beta$-glucosidase value $(\bar{x}) \pm 1$ S.D. (vertical lines) obtained for the normal sample is indicated.

\section{TABLE I}

COMPARISON OF THE RESULTS * OF LEUKOCYTE $\beta$-GLUCOSIDASE DETERMINATION ** IN TYPE 1 GAUCHER'S DISEASE HETEROZYGOTES AND HOMOZYGOTES, AND IN CONTROI.S (Activity, units/mg protein.)

\begin{tabular}{|c|c|c|c|c|c|c|}
\hline \multirow{3}{*}{$\begin{array}{l}\text { Source of } \\
\text { leukocytes }\end{array}$} & \multicolumn{6}{|c|}{$\beta$-Glucosidase assay procedure } \\
\hline & \multicolumn{2}{|l|}{ A [4] } & \multicolumn{2}{|l|}{$\mathrm{B}[3]$} & \multicolumn{2}{|l|}{$\mathrm{C}[2]$} \\
\hline & $\overline{\text { Mean }}$ & S.D. & Mean & S.D. & Mean & S.D. \\
\hline Controls $(n=22)$ & 18.6 & $3.67(19.7)^{*}$ & 20.4 & $3.84(18.8)$ & 1.89 & $0.405(21.4)$ \\
\hline \multicolumn{7}{|l|}{ Obligate hetero- } \\
\hline zygotes $(n=11)$ & 11.3 & $2.23 \quad(19.7)$ & 13.5 & $2.63(19.5)$ & 1.17 & $0.440(37.6)$ \\
\hline Homozygotes $(n=5)$ & 1.80 & $0.713(39.6)$ & 3.50 & $1.16(33.1)$ & 0.23 & $0.074(32.2)$ \\
\hline Student's $t$ & \multicolumn{2}{|c|}{7.03} & \multicolumn{2}{|c|}{6.11} & \multicolumn{2}{|c|}{4.53} \\
\hline Confidence $p$ level & \multicolumn{2}{|c|}{$<0.001$} & \multicolumn{2}{|c|}{$<0.001$} & \multicolumn{2}{|c|}{$<0.001$} \\
\hline
\end{tabular}

$n$, number of individuals.

* The numbers in parentheses represent the coefficient of variation. 
Thus, any of these procedures could be used with confidence to confirm the diagnosis of Gaucher's disease. However, due to the overlap of the ranges of $\beta$-glucosidase values obtained for the control and heterozygote samples, none of the procedures could clearly confirm the carrier state in all cases. Our interest was in identifying which procedure could be used most reliably for carrier detection; therefore, we sought to quantify the degree of overlap of $\beta$-glucosidase values between controls and heterozygotes for each method.

As a first step, for each assay the differences between the mean $\beta$-glucosidase values obtained for the control and heterozygote groups were tested by the Student $t$ test; the values calculated for $t$ are presented in Table I, along with the confidence level for the hypothesis that these two groups are different. For all three assays, the difference between the means was significant at the $99.9 \%$ level; therefore, all three procedures differentiated between the mean $\beta$-glucosidase value of normal individuals and known carriers. Procedure A gave the largest value for $t, 7.03$, indicating that the difference between the mean $\beta$-glucosidase values for the control and the heterozygote sample was greatest using that procedure. The difference between the means was slightly smaller for procedures $\mathrm{B}$ and $\mathrm{C}$ as indicated by the $t$ values of 6.11 and 4.53 , respectively. The coefficient of variation calculated about the mean $\beta$-glucosidase value for the heterozygote sample indicated that procedures $\mathrm{A}$ and $\mathrm{B}$ produced a smaller degree of dispersion (19.7\% and $19.5 \%$, respectively) than did procedure $C(37.6 \%)$. These results are also illustrated qualitatively in Fig. 1 which shows that the observed range of $\beta$-glucosidase values for heterozygotes was narrower when enzyme activity was determined using either procedure A or B.

The performance of a biochemical test in distinguishing between the normal and carrier individuals can be evaluated by the method proposed by Gold [7] which applies Baye's theorem to probability density functions. This mathematical evaluation calculates the probability of heterozygosity using the desired confidence level, 0.01 in most cases, and the frequency of the mutant allele in the population. Delvin [8], using a bivariate form of the analysis, developed a counseling curve for the evaluation of Tay-Sachs carrier status which reduced the number of false classifications to $5 \%$ for the control population and $1.5 \%$ for the heterozygote population. Although Gaucher's disease is relatively common among the Ashkenazi Jewish population, the frequency of the mutant allele in the general population is uncertain and it is not yet possible to apply this probability density function analysis to our results.

Recognizing the limitations imposed on the validity of statistics by a small sample size, we used in our analysis the precedent set by similar analyses of phenylketonuria and Tay-Sachs disease carriers $[7,8]$, which assumes that enzyme activity levels in both the control and heterozygote samples approximate Gaussian distributions. Assuming that $\beta$-glucosidase levels also approximate a normal distribution, we have established the minimum level of $\beta$-glucosidase for the normal population as being one standard deviation below the control mean when analyzed by any of the three assays. Our reason for making this choice of one standard deviation rather than some other minimum value is defended in the following discussion.

Using simple statistical procedures one can predict how often a heterozygous 
individual will be misclassified as normal by determining the extent of overlap of the tails of the two normal curves which can be fitted to the control and heterozygote data. Using one standard deviation below the control mean to define the highest level of $\beta$-glucosidase activity expected in the heterozygote population, one would expect $5.2 \%$ of the known heterozygotes to show $\beta$-glucosidase activity levels greater than this cut-off value when measured using procedure $\mathrm{A}, 12.3 \%$ using procedure $\mathrm{B}$ and $23.6 \%$ using procedure $\mathrm{C}$. Therefore, of the three procedures tested, procedure $\mathrm{A}$ yields the fewest false negative results. It should be noted that $16 \%$ of the true normal population will be expected to exhibit $\beta$-glucosidase levels which fall more than one standard deviation below the mean. The choice of a minimum "normal" level of $\beta$-glucosidase greater than one standard deviation below the mean value for an assay would result in fewer false positive indications but would necessarily cause an increase of false negative results. The absence of a test which perfectly discriminates between the two samples forces one to weigh the cost of a false positive against that of a false negative result. To underscore the potential difficulties involved in carrier testing, Table II presents the results of a second study performed for the family of a 17-year-old girl who died with type 1 Gaucher's disease, demonstrating that we were unable to confirm the carrier status of the mother using radiolabeled glucocerebroside as the substrate for the leukocyte and fibroblast glucocerebrosidase assay.

Thus, $\beta$-glucosidase assay procedures $\mathrm{A}$ and $\mathrm{B}$ provide the greatest discrimination between the control and heterozygote samples, and the smallest degree of dispersion

TABLE II

RESULTS OF THE GLUCOCEREBROSIDASE ASSAY USING LEUKOCYTES AND FIBROBLASTS AS THE SOURCE OF ENZYME TO DETERMINE CARRIER STATUS WITHIN ONE FAMILY

\begin{tabular}{|c|c|c|}
\hline & \multicolumn{2}{|c|}{$\begin{array}{l}\text { Glucocerebrosidase activity * } \\
\text { (units } / \mathrm{mg} \text { protein) }\end{array}$} \\
\hline & leukocytes & fibroblasts \\
\hline \multicolumn{3}{|l|}{ Controls } \\
\hline Mcan & $5.73 \pm 1.04$ & $132 \pm 17.1$ \\
\hline Range & $4.45-7.67$ & $121-151$ \\
\hline$n$ & 17 & 3 \\
\hline \multicolumn{3}{|c|}{ Heterozygotes } \\
\hline Mean & $3.19 \pm 0.46$ & $100 \pm 32.4$ \\
\hline Range & $2.62-4.08$ & $62.7-121$ \\
\hline$n$ & 10 & 3 \\
\hline \multicolumn{3}{|l|}{ Family } \\
\hline Mother & 9.92 & 155 \\
\hline Father & 4.70 & 95.9 \\
\hline Sibling & 3.62 & 52.7 \\
\hline
\end{tabular}

* Glucocerebrosidase was assayed using the authentic substrate according to the procedure of Miller et al. [9].

$n$, number of individuals. 
about these two means. Of these two procedures, $\mathrm{A}$ is expected to produce the lowest number of false negative classifications of true heterozygotes. If the three analytical methods used for these studies were completely independent, the combined use to calculate a single variable form of linear combination of the form $\mathrm{L}=\lambda_{1} x_{1}+\lambda_{2} x_{2}$ $+\lambda_{3} x_{3}$ would reduce the probability of misclassification to less than $2 \%$. However, these determinations are not independent and the various combinations of two analyses or all three determined by discriminant function analysis do not significantly reduce the probability of misclassification as determined by the CBE assay alone. These results indicate that the CBE-dependent $\beta$-glucosidase assay can be used for the detection of carriers of Gaucher's disease in most cases.

This report also provides the first documentation of the suitability of the conduritol B epoxide-dependent fluorometric assay, initially developed using liver as the source of enzyme [4], for estimation of the glucocerebrosidase content of leukocytes.

\section{Acknowledgements}

This work was supported by grants to R.H.G. from the National Institutes of Health (AM 17465) and the National Foundation, March of Dimes, and by a grant to N.S.R. from the National Institutes of Health (NS 03192). We are grateful for the technical assistance of Kathy Baca, Lorna Kropcho and Joyce Sweeney.

\section{References}

1 Fredrickson, D.S. and Sloan, H.R. (1972) Glucosyl ceramide lipidoses: Gaucher's disease. In: The Metabolic Basis of Disease, (Stanbury, J.B., Wyngaarden, J.B. and Fredrickson, D.S., eds.), pp. 730-759, McGraw-Hill, New York

2 Beutler, E. and Kuhl, W. (1970) The diagnosis of the adult type of Gaucher's disease and its carrier state by demonstration of deficiency of $\beta$-glucosidase activity in peripheral blood. J. Lab. Clin. Med. 76, 747-755

3 Peters, S.P., Lee, R.E. and Glew, R.H. (1975) A microassay for Gaucher's disease. Clin. Chim. Acta 60, 391-396

4 Daniels, L.B., Glew, R.H., Radin, N.S. and Vunnam, R.R. (1980) A revised fluorometric assay for Gaucher's disease using conduritol- $\beta$-epoxide with liver as the source of $\beta$-glucosidase. Clin. Chim. Acta 106, 155-163

5 Vunnam, R.R. and Radin, N.S. (1981) Inhibitors of cerebroside metabolism. In: Methods in Enzymology. Vol. 72 (J. Lowenstein. ed.), Academic Press, New York, in press

6 Bradford, M.M. (1976) A rapid and sensitive method for the quantitation of microgram quantities of protein utilizing the principle of protein-dye binding. Anal. Biochem. 72, 248-254

7 Gold, R.J.M., Maag, U.R., Neal, J.L. and Scriver, C.R. (1974) The use of biomedical data in screening for mutant alleles and in genetic counseling. Ann. Hum. Genet. 37, 315-326

8 Delvin, E., Pottier, A., Scriver, C.R. and Gold, R.J.M. (1974) The application of an automated hexosaminidase assay to genetic screening. Clin. Chim. Acta 53, 135-142

9 Miller, R.R., Peters, S.P., Kuhlenschmidt, M.S. and Glew, R.H. (1976) The use of ion-exchange resins in the application of protein samples to gel filtration columns. Anal. Biochem. 72, 45 48 